\title{
The biology of three Mexican-American species of Triatominae (Hemiptera: Reduviidae): Triatoma recurva, Triatoma protracta and Triatoma rubida
}

\author{
José Alejandro Martínez-Ibarra/+, Edgar Paredes-González ${ }^{3}$, Ángel-Licón-Trillo ${ }^{4}$, \\ Oziel Dante Montañez-Valdez ${ }^{2}$, Gonzalo Rocha-Chávez ${ }^{2}$, Benjamín Nogueda-Torres ${ }^{5}$

\begin{abstract}
'Área de Entomología Médica ²Departamento de Desarrollo Regional, Centro Universitario del Sur, Universidad de Guadalajara, Ciudad Guzmán, Jalisco, México ${ }^{3}$ Departamento de Ciencias Químico Biológicas y Agropecuarias, Universidad de Sonora, Unidad Norte Caborca, Caborca, Sonora, México ${ }^{4}$ Facultad de Medicina, Universidad Autónoma de Chihuahua, Chihuahua,
\end{abstract} \\ Chihuahua, México ${ }^{5}$ Becario de Comisión de Operación y Fomento de Actividades Académicas del Instituto Politécnico Nacional, \\ Escuela Nacional de Ciencias Biológicas, Carpio y Plan de Ayala, Colonia Casco de Santo Tomás, México, D.F.
}

The values of biological parameters related to hatching, lifespan, the number of blood meals between moults, mortality, time lapse before the beginning of feeding, feeding time and defecation delay for each instar of three MexicanAmerican species of Triatominae, Triatoma recurva, Triatoma protracta (former subspecies protracta) and Triatoma rubida (former subspecies uhleri), were evaluated and compared. No significant $(p>0.05)$ differences were recorded among the three species with respect to the average time required to hatch. This time was approximately 19 days. The average egg-to-adult development time was significantly $(p<0.05)$ shorter for $\mathrm{T}$. rubida. The number of blood meals at each nymphal instar varied from one-five for each species. The mortality rates were higher for the first-instar nymphs of the three species studied. The mean time lapse before the beginning of feeding was between 0.3-3 min for most nymphs of all instars of each species studied. The mean feeding time was the longest for T. recurva, followed by $\mathrm{T}$. protracta. The defecation delay was less than 10 min for $\mathrm{T}$. recurva and T. rubida. Given these results, only T. rubida should be considered an important potential vector of Trypanosoma cruzi transmission to humans in areas of Mexico where these species exist, whereas T. recurva and T. protracta would be of secondary importance.

Key words: North America - triatomines - biology - laboratory conditions

Biological information is widely available for the 13 most common domestic triatomines (Hemiptera: Reduviidae: Triatominae) among the 30 species described in Mexico (Martínez-Ibarra et al. 2007, Salazar-Schettino et al. 2010). Information about the remaining species is scarce, primarily because these species have rarely been collected and are difficult to raise under laboratory conditions. Three of these rare species are Triatoma recurva (Stal), Triatoma protracta (Uhler) and Triatoma rubida (Uhler). Although these three species are considered to be of low epidemiological importance, specimens of at least two of these species (T. recurva and T. rubida) collected from inside human dwellings were found to be infected with Trypanosoma cruzi (Paredes-González et al. 2001, Licón-Trillo 2006, Breniere et al. 2010, Licón-Trillo et al. 2010). Studies on the behaviour of triatomine species provide a greater understanding of the habits of these insects and therefore facilitate improved decision-making regarding the priorities for vector control. To our knowledge, there has been no study of the biological parameters (life cycle and feeding and defecation behaviours) of $T$. recurva; in contrast, two recent studies were devoted to the examination of certain behaviours of $T$. protracta (Martínez-Ibarra et al. 2007, Klotz et al. 2009) and three studies focused on T. rubida (Martínez-Ibarra et al. 2005,

+Corresponding author: aibarra@cusur.udg.mx

Received 28 October 2011

Accepted 15 February 2012
Klotz et al. 2009, Reisenman et al. 2011). Even though the biological parameters of the two latter species have been studied previously, it is necessary to determine the particular behaviours of geographically distinct populations of the same species because it is likely that differing environmental conditions result in different behaviours for distinct populations of the same triatomine species (Licón-Trillo et al. 2010).

As part of a series of studies on the biology of Mexican Triatominae, a study of the feeding and defecation behaviours and the life cycles of three Triatominae species of secondary importance in the transmission of T. cruzi to human populations in Mexico was conducted.

\section{MATERIALS AND METHODS}

A laboratory colony of T. recurva established in 2009 from specimens collected in Jesús María, Nayarit, Mexico, was used. A colony of $T$. protracta (morphologically similar to the synonymised subspecies protracta) was established in 2008 with specimens originally obtained from Caborca, Sonora, Mexico. In addition, a colony of $T$. rubida (morphologically similar to the synonymised subspecies uhleri) from Saucillo, Chihuahua, was included. The colonies were maintained at $25^{\circ} \mathrm{C} \pm 1^{\circ} \mathrm{C}$ and $50 \%$ relative humidity $(\mathrm{RH}) \pm 5 \% \mathrm{RH}$ to match the typical habitat conditions of the three species. The colonies were fed on immobilised and anaesthetised New Zealand rabbits on a weekly basis. These rabbits were anaesthetised following the Norma Official Mexicana regulations with $0.25 \mathrm{~mL} / \mathrm{kg}$ of ketamine delivered intramuscularly (SAGARPA 1999). 
Eggs from 20-25 mating pairs of each studied species were grouped based on the date of oviposition for a period of one week to initiate a cohort of each species of 200 eggs each. After eclosion, groups of first-instar nymphs from each species were separated individually into plastic containers $(5.5 \mathrm{~cm}$ diameter $\times 10.5 \mathrm{~cm}$ height) with a centre support of absorbent cardboard. Three days after eclosion, each cohort of nymphs was individually fed on immobilised and anaesthetised (as previously described) New Zealand rabbits for a 1-h period; the nymphs were fed weekly thereafter. The nymphs were observed from the beginning of feeding until $1 \mathrm{~h}$ postfeeding to record the feeding and defecation behaviours. To estimate the potential of three triatomine species studied to serve as transmission vectors, only the data on the postfeeding defecation times were considered in the calculation of the defecation delay, as in Zeledón et al. (1977) The insects were maintained in a dark incubator at $25^{\circ} \mathrm{C} \pm 1{ }^{\circ} \mathrm{C}$ and $50 \% \mathrm{RH} \pm 5 \% \mathrm{RH}$ with a $12 / 12 \mathrm{~h}$ (light/dark) photoperiod and were checked daily for ecdysis or death.

From among the insects that completed development into adults, 10 adult pairs from each cohort were placed in individual containers $(5.5 \mathrm{~cm}$ diameter $\times 10.5 \mathrm{~cm}$ height) and maintained as previously described to determine the oviposition patterns.

Variables having a normal distribution were compared using Student's $t$-test or analysis of variance (ANOVA). For the ANOVA, post hoc comparisons were performed with the Scheffé test. A Wilcoxon nonparametric test was used to analyse the variables that did not follow a normal distribution. The chi-squared test was used to compare frequencies. Differences were considered significant when $\mathrm{p}<0.05$.

\section{RESULTS}

The egg eclosion rate was greater than $66 \%$ in all cohorts and reached $72.5 \%$ for $T$. protracta. The average incubation periods were approximately 19 days for the three species studied and did not differ significantly among the species.

The average egg-to-adult development time varied from four months for T. rubida to 6.7 months for T. protracta and was greater than 8.5 months in T. recurva. The differences in the development times between species were significant (Table I).

The average number of blood meals between moults did not differ significantly among the three species (Table I). T. rubida had a significantly lower mortality rate than the other two species; no significant difference in the mortality rate was found between $T$. recurva and T. protracta (Table II). The mean time lapse between the presentation of the blood meal source and the beginning of feeding was between 0.3-3 min for the nymphs of all instars of each species with the exception of the fifth-instar nymphs of $T$. protracta. No significant differences in this parameter were found among the instars of T. recurva, but the fifth-instar nymphs and adults differed significantly from the remaining four instars of T. protracta. Similarly, the adults of $T$. rubida had significantly longer mean time lapses than the nymphal instars (Table II).
The mean feeding times were longer than $10 \mathrm{~min}$ for all instars of T. recurva and for most instars of $T$. protracta, whereas the feeding times for most instars of T. rubida were shorter than $10 \mathrm{~min}$. For T. recurva, the adults of both sexes had significantly longer feeding times than the nymphs. However, the feeding times for most instars of T. protracta and T. rubida were not significantly different (Table III).

The mean defecation delay was less than 10 min for all nymphal instars and adults of T. recurva and T. rubida (with the exception of the males) and for three nymphal instars (NII, NII and NIV) of T. protracta (Table III).

\section{DISCUSSION}

As for various previously studied triatomine species, such as Triatoma brasiliensis Neiva, Triatoma dimidiata (Latreille) and Triatoma ryckmani Zeledón and Ponce (Daflon-Texeira et al. 2009, Reyes \& Angulo 2009, Zeledón et al. 2010, Reyes-Novelo et al. 2011), the egg eclosion rate was greater than $70 \%$ for two of the three species studied, the exception being T. recurva. All of the species studied had average incubation periods of approximately 19 days, reflecting the favourability of the maintenance conditions for the development of these species. The egg hatching rate for T. protracta $(72.5 \%)$ was similar to the rates observed for three related former subspecies of $T$. protracta (currently synonymised to T. protracta): Triatoma protracta navajoensis Ryckman (74.2\%), Triatoma protracta nahuatlae Ryckman (76\%) and Triatoma protracta zacatecensis Ryckman $(81.9 \%)$, all of which were fed on rabbits (Ryckman 1962, Martínez-Ibarra et al. 2007). The egg eclosion rate of T. rubida in the current study (72\%) was similar to the eclosion rate $(70.5 \%)$ of the former subspecies Triatoma rubida sonoriana (currently synonymised to T. rubida) found in a previous study of specimens from Caborca, a municipality that is distant from the area from which the founder specimens of our T. rubida colony were collected (Martínez-Ibarra et al. 2005). These eclosion rates reflect the potential risk posed by T. protracta and T. rubida in the locations where they are currently distributed (Paredes-González et al. 2001, Licón-Trillo 2006).

The average egg-to-adult development time for T. recurva was similar to the corresponding times for Triatoma gerstaeckeri (Stål) and T. dimidiata (Martínez-Ibarra et al. 2007, Reyes \& Angulo 2009), whereas the development times for T. protracta and T. rubida were shorter. T. gerstaeckeri (Stål) and T. dimidiata are considered among the most important vectors of T. cruzi in Mexico and in Latin America, respectively (Salazar-Schettino et al. 2010).

Approximately $70-80 \%$ of the instars of $T$. recurva required an average of 3.5 meals prior to moulting to the next instar, whereas $T$. protracta and T. rubida needed 2.5 meals prior to moulting. The average numbers of blood meals required for moulting to the next instar for $T$. protracta and T. rubida were similar to the values found for Rhodnius colombiensis (Mejia, Galvão, Jurberg), Rhodnius prolixus (Stål) and Rhodnius ecuadoriensis (Lent and León), whereas the average number of blood meals for T. recurva was higher than the average numbers for these three latter species (Arévalo et al. 2007a, 
TABLE I

Egg to adult development cycle and number of blood meals to moult on Triatoma recurva, Triatoma protracta and Triatoma rubida under laboratory conditions

\begin{tabular}{|c|c|c|c|c|c|c|c|c|c|}
\hline \multirow[b]{2}{*}{ Instar } & \multicolumn{3}{|c|}{ T. recurva } & \multicolumn{3}{|c|}{ T. protracta } & \multicolumn{3}{|c|}{ T. rubida } \\
\hline & $\underset{\text { (n) }}{\text { Nymphs }}$ & $\begin{array}{c}\text { Duration } \\
\text { in days } \\
(\text { mean } \pm \mathrm{SD})\end{array}$ & $\begin{array}{c}\text { Number } \\
\text { of blood meals } \\
(\text { mean } \pm \text { SD) }\end{array}$ & $\begin{array}{c}\text { Nymphs } \\
\text { (n) }\end{array}$ & $\begin{array}{c}\text { Duration } \\
\text { in days } \\
(\text { mean } \pm \mathrm{SD})\end{array}$ & $\begin{array}{l}\text { Number of } \\
\text { blood meals } \\
\text { (mean } \pm \text { SD) }\end{array}$ & $\begin{array}{l}\text { Nymphs } \\
\text { (n) }\end{array}$ & $\begin{array}{c}\text { Duration } \\
\text { in days } \\
(\text { mean } \pm \mathrm{SD})\end{array}$ & $\begin{array}{l}\text { Number of } \\
\text { blood meals } \\
(\text { mean } \pm \text { SD) }\end{array}$ \\
\hline Egg-NI & 133 & $20.7 \pm 2.9$ & - & 145 & $21.1 \pm 7.7$ & - & 137 & $17.4 \pm 4.9$ & - \\
\hline NI-NII & 78 & $14.7 \pm 4.7$ & $2.1 \pm 1.6$ & 103 & $35.4 \pm 14.5$ & $1.6 \pm 0.8$ & 115 & $13.3 \pm 0.3$ & 1. $2 \pm 0.2$ \\
\hline NII-NIII & 74 & $31.1 \pm 14.6$ & $4.3 \pm 2.0$ & 97 & $37.2 \pm 18.3$ & $1.8 \pm 0.7$ & 102 & $15.6 \pm 0.3$ & $1.9 \pm 0.2$ \\
\hline NIII-NIV & 65 & $40.2 \pm 15.6$ & $3.9 \pm 1.8$ & 64 & $47.1 \pm 26.4$ & $2.3 \pm 1.3$ & 95 & $18.7 \pm 0.4$ & $2.7 \pm 0.3$ \\
\hline NIV-NV & 47 & $67.1 \pm 23.3$ & $4.4 \pm 1.7$ & 61 & $43.4 \pm 22.8$ & $2.7 \pm 1.6$ & 89 & $25.6 \pm 0.3$ & $2.9 \pm 0.3$ \\
\hline NV-AD & 29 & $91.1 \pm 22.4$ & $3.1 \pm 1.5$ & 44 & $57.1 \pm 35.8$ & $3.3 \pm 2.1$ & 67 & $36.2 \pm 2.7$ & $4.6 \pm 0.3$ \\
\hline Total & 29 & $259.9 \pm 33.6^{a}$ & $17.6 \pm 4.7^{a}$ & 44 & $201.2 \pm 41.5^{b}$ & $10.5 \pm 2.5^{a}$ & 67 & $125.9 \pm 3.3^{c}$ & $13.3 \pm 0.6^{a}$ \\
\hline
\end{tabular}

similar letters indicate no significant $(\mathrm{p}>0.05)$ differences; SD: standard deviation.

TABLE II

Instar mortality and mean time-lapse for beginning feeding for

Triatoma recurva, Triatoma protacta and Triatoma rubida under laboratory conditions

\begin{tabular}{|c|c|c|c|c|c|c|c|c|c|}
\hline & \multicolumn{3}{|c|}{ T. recurva } & \multicolumn{3}{|c|}{ T. protracta } & \multicolumn{3}{|c|}{ T. rubida } \\
\hline Instar & $\underset{\text { (n) }}{\text { Nymphs }}$ & $\begin{array}{c}\text { Mortality } \\
(\%)\end{array}$ & $\begin{array}{l}\text { Time }(\min ) \\
\text { for starting } \\
\text { a blood meal } \\
(\text { mean } \pm \mathrm{SD})\end{array}$ & $\begin{array}{l}\text { Nymphs } \\
\text { (n) }\end{array}$ & $\begin{array}{c}\text { Mortality } \\
(\%)\end{array}$ & $\begin{array}{l}\text { Time }(\min ) \\
\text { for starting } \\
\text { a blood meal } \\
(\text { mean } \pm \mathrm{SD})\end{array}$ & $\begin{array}{l}\text { Nymphs } \\
\text { (n) }\end{array}$ & $\begin{array}{c}\text { Mortality } \\
(\%)\end{array}$ & $\begin{array}{c}\text { Time }(\mathrm{min}) \\
\text { for starting } \\
\text { a blood meal } \\
(\text { mean } \pm \mathrm{SD})\end{array}$ \\
\hline NI & 133 & 41.4 & $1.3 \pm 0.7^{a}$ & 145 & 29 & $1.5 \pm 0.9^{a}$ & 137 & 16.1 & $1.3 \pm 0.9^{a}$ \\
\hline NII & 78 & 3 & $1.1 \pm 0.3^{a}$ & 103 & 4.1 & $1.9 \pm 1.8^{a}$ & 115 & 9.5 & $1.8 \pm 1.4^{a}$ \\
\hline NIII & 74 & 6.8 & $0.5 \pm 0.3^{a}$ & 97 & 22.7 & $2.9 \pm 2.1^{a}$ & 102 & 5.1 & $3.1 \pm 1.1^{a}$ \\
\hline NIV & 65 & 13.5 & $1.5 \pm 1.4^{a}$ & 64 & 2.1 & $1.2 \pm 1.1^{a}$ & 95 & 4.4 & $1.7 \pm 1.4^{a}$ \\
\hline NV & 47 & 13.5 & $0.6 \pm 0.4^{a}$ & 61 & 11.7 & $11.1 \pm 5.5^{b}$ & 89 & 16.1 & $1.8 \pm 1.5^{a}$ \\
\hline Female & 16 & - & $2.3 \pm 1.1^{a}$ & 21 & - & $12.6 \pm 4.9^{b}$ & 34 & - & $9.6 \pm 4.4^{b}$ \\
\hline Male & 13 & - & $2.4 \pm 1.4^{a}$ & 23 & - & $12.3 \pm 5.2^{b}$ & 33 & - & $10.3 \pm 5.8^{b}$ \\
\hline Total & - & $78.2^{a}$ & - & - & $69.6^{a}$ & - & - & $51.2^{b}$ & - \\
\hline
\end{tabular}

similar letters indicate no significant $(\mathrm{p}>0.05)$ differences; SD: standard deviation.

TABLE III

Feeding and defecation times for Triatoma recurva, Triatoma protacta and Triatoma rubida under laboratory

\begin{tabular}{|c|c|c|c|c|c|c|c|c|c|}
\hline & \multicolumn{3}{|c|}{ T. recurva } & \multicolumn{3}{|c|}{ T. protracta } & \multicolumn{3}{|c|}{ T. rubida } \\
\hline Instar & $\underset{\text { (n) }}{\text { Nymphs }}$ & $\begin{array}{l}\text { Feeding times } \\
(\min ) \\
(\text { mean } \pm \text { SD) }\end{array}$ & $\begin{array}{c}\text { Defecation } \\
\text { time } \\
\text { (mean } \pm \mathrm{SD})\end{array}$ & $\begin{array}{l}\text { Nymphs } \\
\text { (n) }\end{array}$ & $\begin{array}{l}\text { Feeding times } \\
\quad(\min ) \\
(\text { mean } \pm \text { SD) }\end{array}$ & $\begin{array}{c}\text { Defecation } \\
\text { time } \\
\text { (mean } \pm \mathrm{SD})\end{array}$ & $\begin{array}{l}\text { Nymphs } \\
\text { (n) }\end{array}$ & $\begin{array}{c}\text { Feeding times } \\
(\min ) \\
(\text { mean } \pm \text { SD) }\end{array}$ & $\begin{array}{c}\text { Defecation } \\
\text { time } \\
\text { (mean } \pm \mathrm{SD})\end{array}$ \\
\hline NI & 133 & $11.4 \pm 5.4^{a}$ & $\pm 0.3^{a}$ & 145 & $9.2 \pm 4.6^{a}$ & $12.4 \pm 8.0^{a}$ & 137 & $7.9 \pm 0.8^{a}$ & $1.3 \pm 0.4^{a}$ \\
\hline NII & 78 & $14.9 \pm 7.5^{a}$ & $1.2 \pm 0.2^{a}$ & 103 & $9.9 \pm 3.8^{a}$ & $8.4 \pm 7.7^{a, b}$ & 115 & $10.1 \pm 1.1^{a}$ & $4.7 \pm 0.8^{a}$ \\
\hline NIII & 74 & $15.8 \pm 2.7^{a}$ & $0.8 \pm 0.1^{a}$ & 97 & $11.4 \pm 5.7^{a}$ & $6.9 \pm 9.5^{b}$ & 102 & $8.7 \pm 1.2^{a}$ & $3.6 \pm 0.9^{a}$ \\
\hline NIV & 65 & $13.9 \pm 6.4^{a}$ & $0.6 \pm 0.3^{a}$ & 64 & $13.0 \pm 5.2^{a}$ & $5.6 \pm 6.3^{b}$ & 95 & $7.1 \pm 1.2^{a}$ & $3.5 \pm 0.9^{a}$ \\
\hline NV & 47 & $12.9 \pm 8.9^{a}$ & $0.7 \pm 0.1^{a}$ & 61 & $11.9 \pm 6.7^{a}$ & $15.9 \pm 7.2^{a}$ & 89 & $8.1 \pm 1.3^{a}$ & $5.2 \pm 0.7^{a}$ \\
\hline Female & 16 & $25.8 \pm 10.9^{b}$ & $\pm 1.1^{a}$ & 21 & $14.9 \pm 4.9^{a, b}$ & $17.4 \pm 8.4^{a, c}$ & 34 & $12.1 \pm 1.8^{a, b}$ & $7.7 \pm 3.1^{a}$ \\
\hline Male & 13 & $28.9 \pm 12.7^{b}$ & $2.3 \pm 1.4^{a}$ & 23 & $16.7 \pm 6.8^{b}$ & $19.7 \pm 11.5^{c}$ & 33 & $13.4 \pm 1.9^{b}$ & $25.7 \pm 4.1^{b}$ \\
\hline
\end{tabular}

similar letters indicate no significant $(\mathrm{p}>0.05)$ differences; SD: standard deviation. 
Villacís et al. 2008). Because an increase in the number of vector-host interactions (for blood feeding) increases the probability of transmission of T. cruzi to hosts (Rocha et al. 2001), the three currently studied species could be considered potentially epidemiologically important with respect to $T$. cruzi transmission to human populations.

The mortality rates of T. rubida were low (the lowest of the 3 species studied). This finding may be one reason that $T$. rubida is by far the most common of the three species in virtually its entire area of distribution (Licón-Trillo 2006, Reisenman et al. 2010). In contrast, the mortality rates of T. recurva were high (the highest of the three species studied). This finding could partially explain the low abundance of this species in its area of distribution (Breniere et al. 2010, Licón-Trillo et al. 2010, Bern et al. 2011). Similar mortality rates have been recorded for Rhodnius neglectus Lent and Rhodnius robustus Larrouse, the two principal wild triatomine species (corresponding to $T$. recurva) in Brazil (Barreto-Santana et al. 2011).

As observed for some other triatomine species, the instar-specific mortality rates of the species studied had an irregular pattern. The highest percentages of mortality for two (T. recurva and T. rubida) of the three species were observed in the first or fifth nymphal instar, as reported for other triatomine species (Martínez-Ibarra et al. 2008, Barreto-Santana et al. 2011). As reported for the species previously cited, mortality in the youngest nymphs appeared to be caused by the inability of the insects to feed because dead triatomines were generally found without significant intestinal content. In contrast, the mortality of older nymphs appeared to occur during moulting.

The mean time lapse before the beginning of feeding was less than 2 min for most instars of the three species studied. Similar behaviour was recorded for cohorts of Mepraia spinolai (Porter), T. rubida (from southwestern USA), $R$. colombiensis, $R$. prolixus, $R$. neglectus and $R$. robustus, which are considered potentially important vectors for the transmission of T. cruzi (Alzamora et al. 2007, Arévalo et al. 2007b, Klotz et al. 2009, BarretoSantana et al. 2011, Reisenman et al. 2011). The short mean time lapse before the beginning of feeding implies efficient feeding behaviour. Such efficient feeding increases the probability of survivorship of the species (Guarneri et al. 2000).

The mean feeding times were longer than $10 \mathrm{~min}$ for all instars of T. recurva, for most instars of T. protrac$t a$ and for the adults of T. rubida. These mean feeding times were similar to those for M. spinolai, T. rubida and T. protracta (both Triatoma species from southwestern USA) and for $R$. neglectus and $R$. robustus (Alzamora et al. 2007, Klotz et al. 2009, Barreto-Santana et al. 2011, Reisenman et al. 2011). According to Zeledón et al. (1977), species that feed longer than 10 min could be considered potentially important vectors of $T$. cruzi because prolonged vector-host contact could increase the probability of the interruption of feeding, thereby increasing the risk of contact with the faeces of these insects.

The data on defecation patterns showed that for a fraction (less than 10\%) of defecation events, the specimens of the three studied species in all instars tended to defecate before finishing a blood meal. The defecation delay was less than 10 min for all studied instars of $T$. recurva and T. rubida (with the exception of the males in the latter species) and for the second, third and fourthinstar nymphs of T. protracta. Zeledón et al. (1977) hypothesised that the triatomines that defecate before 10 min postfeeding could be considered potentially effective transmitters of $T$. cruzi because these triatomines are usually in contact with their host for at least $10 \mathrm{~min}$. In the light of this hypothesis, the following instars of the three species studied could be considered effective vectors of T. cruzi: all instars of T. recurva, almost all instars of T. rubida and the second, third and fourth-instar nymphs of $T$. protracta.

The parameters studied support the conclusion that the three species considered herein may have different potentials to transmit $T$. cruzi to humans in those areas of Mexico where these species currently exist. T. rubida could be considered an efficient vector, whereas T. recurva and T. protracta would be of secondary importance, as previously suggested in other field studies (Kjos et al. 2009, Breniere et al. 2010, Licón-Trillo et al. 2010, Reisenman et al. 2010).

\section{REFERENCES}

Alzamora A, Correa P, Gaggero E, Acuña-Retamar M, Cattan PE 2007. Conducta de picada y defecación de Mepraia spinolai en dos hospederos frecuentes en su hábitat. Parasitol Latinoam 62: 112-117.

Arévalo A, Carranza JC, Guhl F, Clavijo JA, Vallejo GA 2007a. Comparación del ciclo de vida de Rhodnius colombiensis y Rhodnius prolixus (Hemiptera, Reduviidae, Triatominae) en condiciones de laboratorio. Biomedica 27 (Suppl. 1): 119-129.

Arévalo A, Carranza JC, Guhl F, Clavijo JA, Vallejo GA 2007b. Comparación de los patrones de alimentación y defecación de Rhodnius colombiensis y Rhodnius prolixus (Hemiptera, Reduviidae, Triatominae) en condiciones de laboratorio. Biomedica 27 (Suppl. 1): 101-109.

Barreto-Santana D, Starling J, Gurgel-Goncalvez R, Cuba-Cuba CA 2011. Comparativwe biology and feeding behaviour of Rhodnius neglectus and Rhodnius robustus (Triatominae) under laboratory conditions. Rev Soc Bras Med Trop 44: 490-495.

Bern C, Kjos S, Yabsley MJ, Montgomery SP 2011. Trypanosoma cruzi and Chagas disease in the United States. Clin Microbiol Rev 24: 655-681.

Breniere SF, Bosseno MF, Magallón-Gastélum E, Soto Gutiérrez MM, Kasten-Monges MJ, Barraza-Salas JH, Romero-Paredes JJ, Lozano-Kasten FJ 2010. Community participation and domiciliary occurrence of infected Meccus longipennis in two Mexican villages in Jalisco state. Am J Trop Med Hyg 83: 382-387.

Daflon-Teixeira NF, Carvalho-Costa FA, Chiang RG, Lima MM 2009. Influence of blood meal and mating in reproduction patterns of Triatoma brasiliensis females (Hemiptera: Reduviidae) under laboratory conditions. Mem Inst Oswaldo Cruz 104: 1031-1034.

Guarneri AA, Carvalho MG, Pereira MH, Diotaiuti L 2000. Potencial biologico do Triatoma brasiliensis. Cad Saude Publica 16 (Suppl. 2): 101-104.

Kjos SA, Snowden KF, Olson JK 2009. Biogeography and Trypanosoma cruzi infection prevalence of Chagas disease vectors in Texas, USA. Vector Borne Zoonotic Dis 9: 41-49.

Klotz SA, Dorn P, Klotz JH, Pinnas JL, Weirauch C, Kurtz JR, Schmidt J 2009. Feeding behaviour of triatomines from the southwestern United States. An update on potential risk for transmission of Chagas disease. Acta Trop 111: 114-118. 
Licón-Trillo A 2006. Infección de Triatoma recurva por Trypanosoma cruzi en un campamento minero de Urique, Chihuahua (México). Rev Fac Sal Pub Nut 7: 1-8.

Licón-Trillo A, Balsimelli-De La Peña K, Acosta-Legarda M, LealSolís I, Nogueda-Torres B, Martínez-Ibarra JA 2010. Infección natural por Trypanosoma cruzi en triatominos del centro y norte de México. Bol Malar Salud Ambient 50: 311-313.

Martínez-Ibarra JA, Alejandre-Aguilar R, Paredes-González E, Martínez-Silva MA, Solorio-Cibrián M, Nogueda-Torres B, TrujilloContreras F Novelo-López M 2007. Biology of three species of North American Triatominae (Hemiptera: Reduviidae Triatominae) fed on rabbits. Mem Inst Oswaldo Cruz 102: 925-930.

Martínez-Ibarra JA, Nogueda-Torres B, Paredes González E, AlejandreAguilar R, Solorio-Cibrián M, Barreto SP, Gómez-Estrada HI, Trujillo-García JC 2005. Development of Triatoma rubida sonoriana, Triatoma barberi and Meccus mazzottii (Heteroptera, Reduviidae) under laboratory conditions. J Am Mosq Cont Assoc 21: 310-315.

Martínez-Ibarra JA, Salazar-Schettino PM, Solorio-Cibrián M, Bravo MC, Novelo-López M, Vences MO, Montes-Ochoa JY, Nogueda-Torres B 2008. Influence of temperature and humidity on the biology of Triatoma mexicana (Hemiptera: Reduviidae: Triatominae) under laboratory conditions. Mem Inst Oswaldo Cruz 103: 719-723.

Paredes-González EA, Valdez-Miranda J, Nogueda-Torres B, Alejandre-Aguilar R, Canett-Romero R 2001. Vectorial importance of triatomine bugs (Hemiptera: Reduviidae) in Guaymas, México. Rev Lat Microbiol 43: 119-122.

Reisenman CE, Gregory T, Guerenstein PG, Hildebrand JG 2011. Feeding and defecation behaviour of Triatoma rubida (Uhler, 1984) (Hemiptera: Reduviidae) under laboratory conditions and its potential role as a vector of Chagas disease in Arizona, USA. Am J Trop Med Hyg 85: 648-656.

Reisenman CE, Lawrence G, Guerestein PG, Gregory T, Dotson E, Hildebrand JG 2010. Infection of kissing bugs with Trypanosoma cruzi, Tucson, Arizona, USA. Emerg Infect Dis 16: 400-405.
Reyes M, Angulo VM 2009. Ciclo de vida de Triatoma dimidiata Latreille, 1811 (Hemiptera, Reduviidae) en condiciones de laboratorio: producción de ninfas para ensayos biológicos. Biomedica 29: $119-126$.

Reyes-Novelo E, Ruiz-Piña HA, Escobedo-Ortegón J, Barrera-Pérez MA 2011. Biología y ecología de Triatoma dimidiata, algunos aspectos de estudio. Dugesiana 18: 11-16.

Rocha DS, Jurberg J, Carcavallo RU, Presgrave OA, Cunha V, Galvão C 2001. Influence of temperature and humidity on the nymphal development of Rhodnius robustus. Rev Saude Publica 35: 400-406.

Ryckman R 1962. Biosystematics and hosts of the Triatoma protracta complex in North America. Univ California Publ Ent 27: 93-239.

SAGARPA - Secretaría de Agricultura, Ganadería, Desarrollo Rural, Pesca y Alimentación 1999. [cited 13 October 2011]. Norma Oficial Mexicana NOM-062-ZOO-1999. Especificaciones técnicas para la producción, cuidado y uso de los animales de laboratorio. Available from: fmvz.unam.mx/fmvz/principal/ archivos/062ZOO.pdf.

Salazar-Schettino PM, Rojas-Wastavino GE, Cabrera-Bravo M, Bucio-Torres M, Martínez-Ibarra JA, Monroy-Escobar MC, RodasRetana A, Guevara-Gómez Y, Vences-Blanco MO, Ruiz-Hernández AL, Torres-Gutiérrez E 2010. A revision of thirteen species of Triatominae (Hemiptera: Reduviidae) vectors of Chagas disease in Mexico. J Selva Andina Res Soc 1: 57-80.

Villacís AG, Arcos-Terán L, Grijalva MJ 2008. Life cycle, feeding and defecation patterns of Rhodnius ecuadoriensis (Lent \& León 1958) (Hemiptera: Reduviidae: Triatominae) under laboratory conditions. Mem Inst Oswaldo Cruz 103: 690-695.

Zeledón R, Alvarado R, Jirón JF 1977. Observations on the feeding and defecation patterns of three triatomine species (Hemiptera: Reduviidae). Acta Trop 34: 65-77.

Zeledón R, Cordero M, Marroquín R, Lorosa ES 2010. Life cycle of Triatoma ryckmani (Hemiptera: Reduviidae) in the laboratory, feeding patterns in nature and experimental infection with Trypanosoma cruzi. Mem Inst Oswaldo Cruz 105: 99-102. 